\title{
Wip1 is associated with tumorigenity and metastasis through MMP-2 in human intrahepatic cholangiocarcinoma
}

\author{
Sulai Liu ${ }^{1}$, Bo Jiang ${ }^{1}$, Hao Li ${ }^{1}$, Zili He ${ }^{1}$, Pin Lv ${ }^{1}$, Chuang Peng ${ }^{1}$, Yonggang Wang ${ }^{1}$, \\ Wei Cheng ${ }^{1}$, Zhengquan $X_{u^{2}}$, Wei Chen ${ }^{3}$, Zhengkai Liu ${ }^{1}$, Bao Zhang ${ }^{1}$, Shengqian \\ Shen ${ }^{1}$ and Shuanglin Xiang ${ }^{4}$ \\ ${ }^{1}$ Department of Hepatobiliary Surgery/Hunan Research Center of Biliary Disease, Hunan Provincial People's Hospital/The \\ First Affiliated Hospital of Hunan Normal University, Changsha, Hunan Province, People's Republic of China \\ ${ }^{2}$ Department of Orthopaedics, The First Affiliated Hospital of Fujian Medical University, Fuzhou, Fujian Province, People's \\ Republic of China \\ ${ }^{3}$ Department of Thoracic, The First Affiliated Hospital of Anhui Medical University, Hefei, Anhui Province, People's Republic \\ of China \\ ${ }^{4}$ Key Laboratory of Protein Chemistry and Developmental Biology of State Education Ministry of China, College of Life \\ Science, Hunan Normal University, Changsha, Hunan Province, People's Republic of China
}

Correspondence to: Bo Jiang, email: hepatojiangbo@163.com

Keywords: intrahepatic cholangiocarcinoma, Wip 1, MMP-2, prognosis

Received: March 26, $2017 \quad$ Accepted: April 26, $2017 \quad$ Published: May 23, 2017

Copyright: Liv et al. This is an open-access article distributed under the terms of the Creative Commons Attribution License (CC-BY), which permits unrestricted use, distribution, and reproduction in any medium, provided the original author and source are credited.

\section{ABSTRACT}

Wip1 has been shown to correlate with the metastasis/invasion of several tumors. This study was designed to investigate the clinical significance and biological function of Wip1 in intrahepatic cholangiocarcinoma (ICC). The expression of Wip1 was investigated in sixty human ICC biopsy samples by immunohistochemistry. Transient and stable knockdown of Wip1 in two human ICC cells (ICC-9810 and SSP25) were established using short hairpin RNA expression vector. Immunohistochemistry revealed that Wip1 was up-regulated in human ICC tissues (47/60, 78.3\%). High levels of Wip1 in human ICC correlated with metastasis to the lymph metastasis $(P=0.022)$. Genetic depletion of Wip1 in ICC cells resulted in significantly inhibited proliferation and invasion compared with controls. Most importantly, Wip1 downregulation impaired tumor migration capacity of ICC cells in vivo. Subsequent investigations revealed that matrix metalloproteinase-2 (MMP-2) is an important target of Wip1. Consistently, in human ICC tissues, Wip1 level was positively correlated with MMP-2 expression. Taken together, our founding indicates that Wip1 may be a crucial regulator in the tumorigenicity and invasion of human ICC, Wip1 exerts its pro-invasion function at least in part through the MMP-2 signaling pathway, suggesting Wip1 as a potential therapeutic target for ICC.

\section{INTRODUCTION}

Intrahepatic cholangiocarcinoma (ICC) is an aggressive malignancy with poor prognosis that makes up $10-25 \%$ of all primary hepatic cancers. However, its mortality and morbidity are increasing in recent years $[1,2]$. On the other hand, ICC arises from the intrahepatic biliary tree and continues to be characterized by a poor prognosis, less than $20 \%$ to $50 \%$ of the patients alive
5 years after curative resection, and a high recurrence/ metastasis rate $[2,3]$. Radical surgical resection remains the first-line approach and presents most effective therapy of cure in the treatment of ICC [4]; however, most patients have advanced disease at the time of diagnosis and are not suitable candidates for surgery $[5,6]$. Therefore, specific and new biomarkers that can indicate the risk of morbidity and recurrence are clearly necessary for the development of novel therapeutic options for patients with ICC. 
Wip1 (wild-type p53-induced phosphatase 1) belongs to PP2C family and is encoded by PPM1D gene, which inhibits p53 functions and activity in cancer cells. Wip1 is emerging as an important oncogene by virtue of its negative control on several key cancer suppressor pathways, including P38-MARK, Dkk3-Wnt, DNA damage response (DDR) [7-11]. Wip1 dephosphorylates many proteins, including ataxia-telangiectasia mutated (ATM), p53, p38, Mdm2, Mdm4, Chk1, Chk2, and UNG2 $[12,13][7]$. These proteins that belong DDR/checkpoint markers, are often decreased in DNA damage response pathways, which contribute to sensing and repairing DNA damage. Others and we previously studies showed that Wipl has been subsequently found amplified and more recently mutated in a significant fraction of human cancers including kidney [14], breast [15], lung [16], ovarian [17], neuroblastoma [18]. Although the abnormalities of Wip1 have been efficiently investigated in some kinds of tumors, there has been no study evaluating the relationship between expression of Wip1 in ICC cells and patients' tissues. In this study, we reported Wip1 expression occurs in ICC tissue specimens, and determined its relationship with the expression of AFP, GGT, Ki67, CA199, P53 and clinicopathological characteristics. Furthermore, we investigated the roles of Wipl expression in biologic behavior of ICC cells.

\section{RESULTS}

\section{The expression of Wip1 was elevated in ICC tissues and associated with hepatic hilar lymph nodes metastasis}

To assess the Wip1 protein expression in ICC species, immunostaining was strictly performed according our previous method $[14,19]$ in 60 pairs of human ICC and normal tissue samples. Immunohistochemistry data showed that Wip1 expression was significantly up-regulated in ICC tissues compared with the normal samples (Figure 1). Wip1 protein was shown mainly in the cytoplasm and membrane of ICC cells, while our data showed Wip1 protein were rare detectable in normal tissues (Figure 1A). In general, high Wip1 expression (++ or +++ ) was observed in 47 of 60 tumor samples $(78.3 \%$; Figure 1C,1D), whereas low Wip1 expression (- or +) was noted in 13 of 60 tumor samples (21.7\%; Figure 1B).

The correlations between Wip1 protein expression and clinicopathological characteristics of ICC were analyzed in Table 1. The level of Wip1 expression in ICC tissues was significantly correlated with nerve infiltration $(\mathrm{P}=0.035)$ and lymphatic metastasis $(\mathrm{P}<0.001)$. Furthermore, there were no significant differences observed between Wip1 expression and other clinicopathologic features, such as gender ( $\mathrm{P}=0.79)$, age $(\mathrm{P}=0.86)$, Tumor differentiation $(\mathrm{P}=0.82)$, HBV infection ( $\mathrm{P}=0.34)$, Tumor focality $(\mathrm{P}=0.75)$, Clinical T stage $(\mathrm{P}=0.32)$ or Vascular invasion $(\mathrm{P}=0.33)$.

\section{Wip1 expression was correlated with P53, CA- 199 and MMP-2 levels in ICC cases}

The association between Wip1 expression and the expression of P53, CA-199, AFP, Ki67, GGT and MMP-2 in ICC cases were shown in Table 2. Our data show that the Wip 1 protein expression was significantly associated with the P53/CA-199/MMP-2 ( $\mathrm{P}=0.014, \mathrm{P}=0.016$ and $\mathrm{P}=0.008$, respectively, Table 1 ). There were no correlation between the expression of Wip1 and any other of immunohistochemical findings, including AFP, Ki67 and GGT in ICC tissues.

\section{Transfection of Wip1-shRNA repressed the proliferation and invasion capacity of ICC-9810 and SSP25 cells}

We then determined the effect of Wip1 on cell proliferation and invasion in two ICC cell lines. We depleted its expression in ICC-9810 and SSP25 cells by shRNAWip1 and established stable cell lines. As shown in Figure 2, the qRT-PCR and Western blot results revealed Wip1 was effectively and functionally suppressed in ICC-9810 and SSP25 cells compared to the scramble control (Figure $2 \mathrm{~A}-2 \mathrm{C}$ ). To further explore the biological role of reduced Wip1 of ICC-9810 and SSP25 cell lines, proliferation assay was performed. CCK-8 cell proliferation assay showed that the decrease in Wip1 expression caused by Wip1-shRNA obviously inhibited the proliferation of ICC-9810 and SSP25 cells (Figure 2D, 2E). Next, we assessed the alterations to the capacity of invasion in ICC-9810 and SSP25 cells lines. As show in Figure 3A-3C, Madrigal invasion assay revealed that the decrease in Wip1 expression caused by Wip1-shRNA significantly inhibited ICC-9810 cells' invasion capacity. Similar results were also obtained in SSP25 cells (Figure $3 \mathrm{D}-3 \mathrm{~F})$. These data vividly indicated that down- regulation of Wip1 inhibits the proliferation and invasiveness of ICC9810 and SSP25 cells.

\section{Transfection of Wip1-shRNA impaired the migration of ICC-9810 and SSP25 cells in vitro}

To examine whether the targeted down-regulation of Wip1 in ICC-9810 and SSP25 cells affects the migration of tumor cells, migration assays were performed. Our results show that cells in the Wip1-shRNA in ICC-9810 group exhibited decreased migration ability compared with the Scramble (Figure 4A-4C). Similar results were found in SSP25 cells tranfected with Wip1-shRNA (Figure 4D-4F). Thus, down-regulation of Wip1 dramatically diminished the migration of ICC-9810 and SSP25 cells in vitro. Consistently, wound healing assays show that cells in the Wip1-shRNA group exhibited decreased migration ability compared with the control (Figure 4G-4H). Similar results were observed in SSP25 cell line. Therefore, down-regulation of Wip1 dramatically decreased the migration of ICC-9810 and SSP25 cells in vitro. 
A
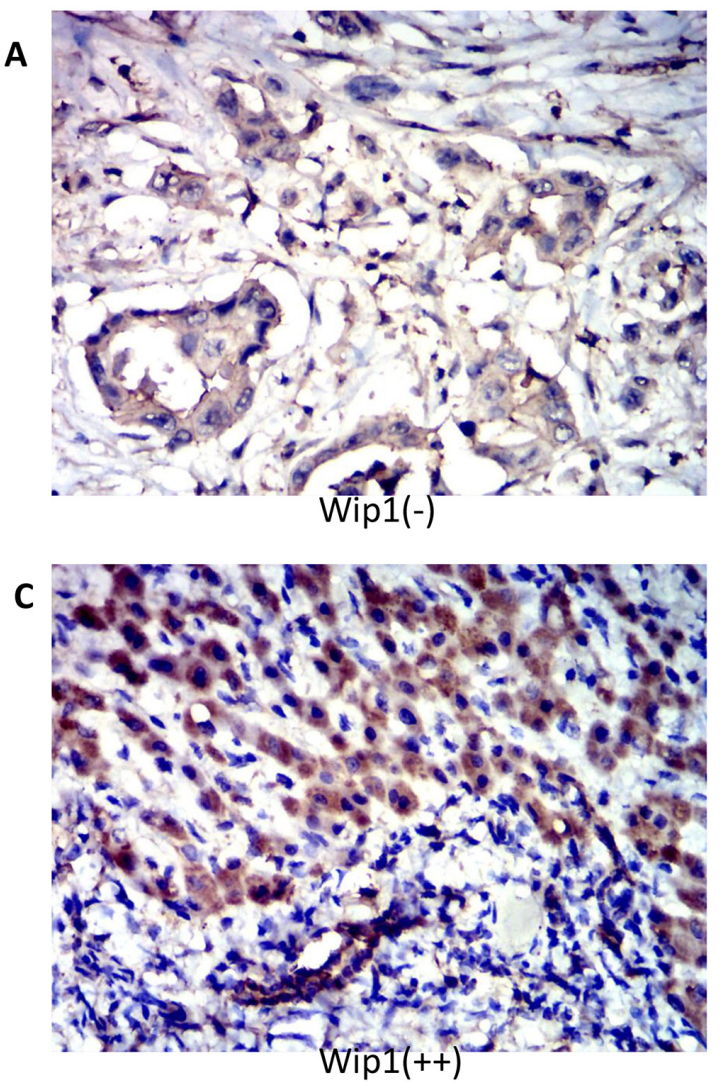
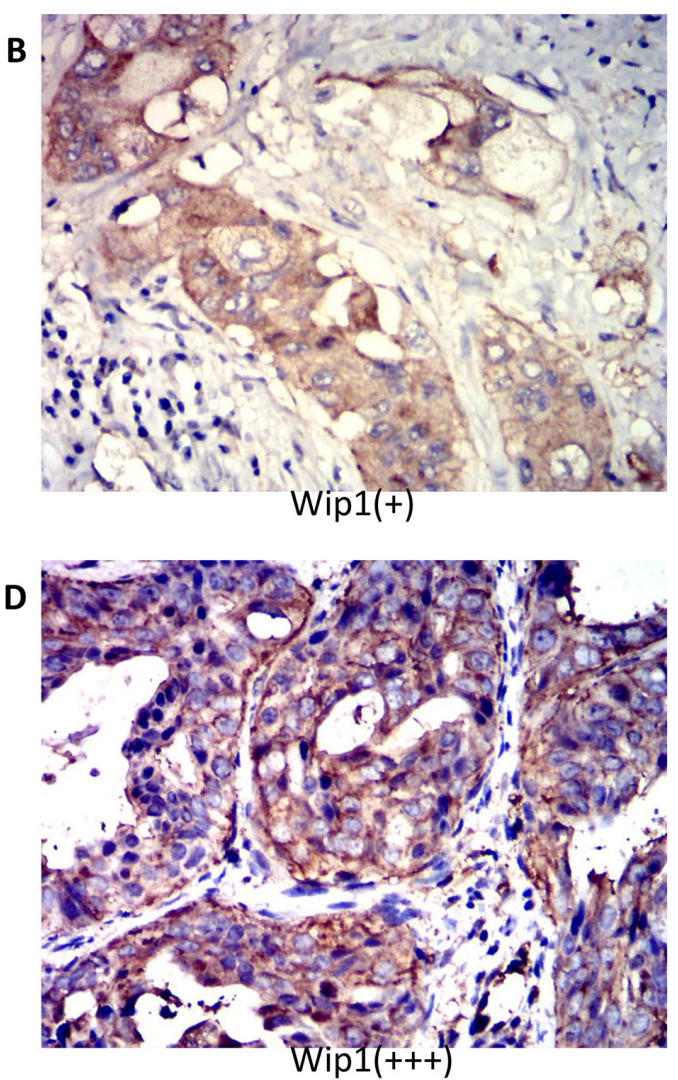
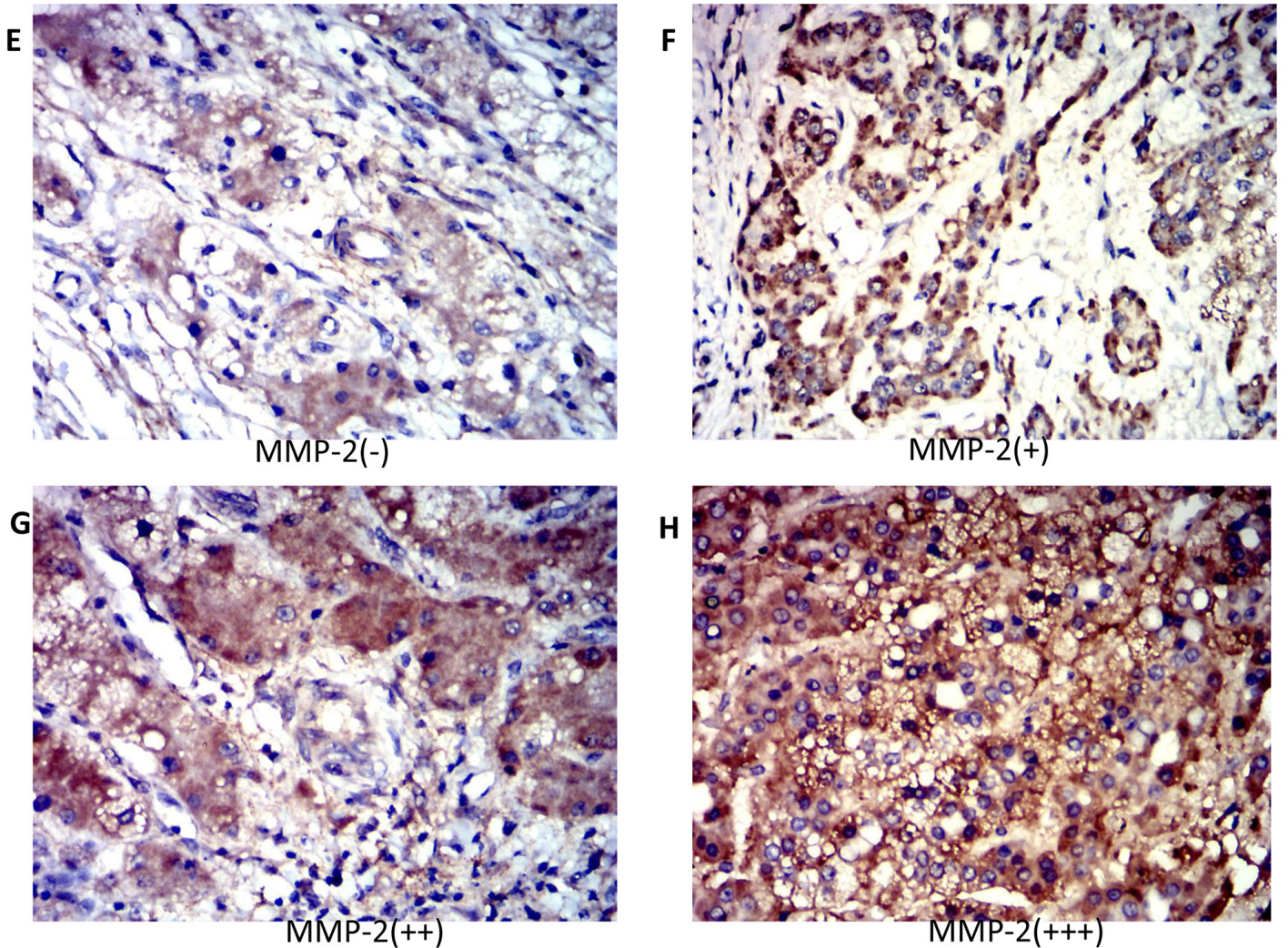

Figure 1: Expression of Wip1 and MMP-2 in human ICC tissues. Immunohistochemistry revealed no staining (-) (A) low staining $(+)$ (B) moderate staining $(++)$ (C) and strong staining $(+++)($ (D) for Wip1 and MMP-2 in human ICC tissue. The Wip1 level was positively correlated with MMP-2 expression in human ICC tissue (A-H). Magnification: 200×;*P $<0.05$. 
Table 1: Correlation between Wip1 expression and 60 patients with ICC

\begin{tabular}{|c|c|c|c|c|}
\hline \multirow[t]{2}{*}{ Variables } & & \multicolumn{3}{|c|}{ Wip1 } \\
\hline & & Positive $(n=47)$ & Negative (n-13) & $\boldsymbol{P}$ \\
\hline \multirow[t]{2}{*}{ Sex } & Male & 27 & 8 & 0.79 \\
\hline & Female & 20 & 5 & \\
\hline \multirow[t]{2}{*}{ Age } & $\leq 60$ & 12 & 3 & 0.86 \\
\hline & $>60$ & 35 & 10 & \\
\hline \multirow[t]{2}{*}{ Tumor differentiation } & Well & 20 & 6 & 0.82 \\
\hline & Poor & 27 & 7 & \\
\hline \multirow[t]{2}{*}{ Nerve infiltration } & Yes & 33 & 5 & 0.035 \\
\hline & No & 14 & 8 & \\
\hline \multirow[t]{2}{*}{ Lymphatic metastasis } & Yes & 35 & 3 & $<0.001$ \\
\hline & No & 12 & 10 & \\
\hline \multirow[t]{2}{*}{ HBV infection } & Yes & 32 & 7 & 0.34 \\
\hline & No & 15 & 6 & \\
\hline \multirow[t]{2}{*}{ Tumor focality } & Solitary & 42 & 12 & 0.75 \\
\hline & Multiple & 5 & 1 & \\
\hline \multirow[t]{2}{*}{ Vascular invasion } & Yes & 21 & 7 & 0.32 \\
\hline & No & 26 & 6 & \\
\hline \multirow[t]{2}{*}{ Clinical T stage } & $\mathrm{T} 1-2$ & 18 & 4 & 0.33 \\
\hline & $\mathrm{T} 3-4$ & 29 & 9 & \\
\hline
\end{tabular}

\section{Knockdown of Wip1 repressed MMP-2 expression in ICC-9810 and SSP25 cells}

We next investigated a potential mechanism for Wip1-mediated ICC cell migration and invasion. Typically, malignant cells could breakage of the basement membrane through secreting Matrix metalloproteinases (MMPs) that digest the extracellular matrix (ECM) proteins. Accumulating studies have revealed that MMP-2 was an important regulator of metastasis in ICC $[20,21]$. Indeed, we have recently found new candidates Wip1 substrate (contain MMP-2), which localizes in the cytoplasm and suppresses cell death signaling linked to ICC (manuscript in preparation). We therefore investigated MMP-2 expression using immunohistochemistry on tissues from all 60 patients with ICC. MMP-2 levels were positively associated with Wip1 expression (Figure 1E-1H and Table 1; $\mathrm{P}=0.039)$. Further more, the expression of Wip1 and MMP-2 in ICC were correlated with hilar lymph nodes metastasis. To further identify the effect of Wip1 expression in ICC cell lines in vitro, our data show the introduction of shRNA-Wip1 remarkably decreased MMP-2 protein expression in ICC-9810 and SSP25 cells (Figure 5A). In accordance with this, the MMP-2 mRNA level was observed significantly lower in transfect Wip1-shRNA cells than Scramble cells $(\mathrm{P}<0.05$; Figure $5 \mathrm{~B})$.
Finally, we established xenograft-using cells treated respectively with ICC-9810 Wip1-shRNA and control cells, and documented the tumor volume weekly. Our data show there was no difference of tumor volume between the ICC-9810 Wip1-shRNA and control groups in the first two weeks (Figure 5C), but the growth of the tumor in the Wip1-shRNA group significantly slowed down since the 3 th week, compared with the control group $(\mathrm{P}<0.05)$. Wip1 and MMP-2 expression in subcutaneous tumors were analyzed by immunohistochemistry. Wip 1 and MMP-2 immunohistochemical stainings in the Wip1shRNA tumors were remarkably lower than that in control, indicating that interference for Wip1 may restrain the proliferation of tumor cells through MMP-2 (Figure 5D).

\section{DISCUSSION}

Wip1, on chromosome 17q22-q23, functions as an oncogene and inhibits p53 activity when overexpressed in proliferation of certain self- renewing cell types, including carcinogens, with advancing age [22]. These features were mainly connected with Wip1 ability to regulate signaling in DNA damage response (DDR) and MAPK kinases pathway p53 network, including p38, p53, ATM, Chk2, and $\gamma$-H2AX [7, 23, 24]. Accumulating 
Table 2: Association between the expression of wip1 and other markers in ICC

\begin{tabular}{|c|c|c|c|}
\hline \multirow[t]{2}{*}{ Variables } & \multicolumn{3}{|c|}{ Wip1 expression } \\
\hline & Positive(n=47) & Negative(n=13) & $P$ \\
\hline CA-199 & & & 0.015 \\
\hline Positive & 40 & 7 & \\
\hline Negative & 7 & 6 & \\
\hline AFP expression & & & \\
\hline Positive & 24 & 8 & 0.5 \\
\hline Negative & 23 & 5 & \\
\hline P53 expression & & & 0.014 \\
\hline Positive & 18 & 10 & \\
\hline Negative & 29 & 3 & \\
\hline Ki67 expression & & & 0.86 \\
\hline Positive & 35 & 10 & \\
\hline Negative & 12 & 3 & \\
\hline GGT expression & & & 0.59 \\
\hline Positive & 22 & 5 & \\
\hline Negative & 25 & 8 & \\
\hline MMP-2 expression & & & 0.008 \\
\hline Positive & 41 & 7 & \\
\hline Negative & 6 & 6 & \\
\hline
\end{tabular}

studies showed that over expression of Wip1 will disrupt multiple pathways implicated in the regulation of p38MAPK-p53 tumor suppressor responses, which caused down target Wnt-p53 dephosphrylation through limiting the p38MAPK-STAT1 pathway, and promoted tumor formation in humans by decreasing p16/p19 levels [11, 25]. Our previous data have indicated that Wip 1 was an oncoprotein and was involved in controlling mechanism in renal carcinoma cells [14]. Sona et al report that Inhibition of Wip1 by GSK2830371 sensitizes breast cancer cells to senescence and to activation of caspase-9 [25]. A recent research article demonstrated that crosstalk among Wip1, CXCR4 and GRK5 promote aggressive phenotype of a medulloblastoma in children [9]. However, the role of Wip1 in the tumorigenicity and metastasis of ICC cells was scarcely investigated. Here, we show that the expression of Wip1 was elevated in ICC tissues, and the over expression of Wip1 was associated with lymph node metastasis. These data indicated that Wip1 may involve in the lymph node metastasis of ICC.

ICC is a fatal primary liver carcinoma, which originating from the intrahepatic bile duct epithelium beyond the second-order bile ducts [5] [26, 27]. ICC is the second most common all primary liver cancers in the worldwide, the actual incidence has been increasing steadily and substantially over the past decades and has a poor outcomes and high mortality rate due to the high invasiveness and recurrence [1,28-30]. Some previous studies reported that Wip1 expression was associated with miR-17-5p through activation of the p38 pathway in hepatocellular carcinoma (HCC)[31]. Zhang L et al show that inhibition of Wip1 can activate the mammalian target of rapamycin complex 1 (mTORC1) pathway and enhance hepatocyte proliferation after hepatectomy [32]. However, in line with another study on Asian patients with HCC $[33,34]$, Our data found Wip1 expression in up to $78.3 \%$ (47/60) of ICC cases, while in none of adjacent cancer tissues, suggesting that ICC and HCC histological appearance were very similar and a significant racial difference.

In this study, our data show that Wip1 was overexpressed in human ICC cases, which was significantly correlated with aggressive phenotypes of cancer cells. Furthermore, our results found that depletion of Wip1 inhibited the proliferation and migration of human ICC cells. Recent reports have indicated that Wip1-knockout mice impaired their tumor formation capacity in vivo. What's more, even when tumors form in these kinds nude mice, the carcinoma cells often show a low proliferation potential [35]. Our in vivo dada show that Wip1 downexpression in nude mice inhibits tumor formation capacity and decreases cancer progression. 


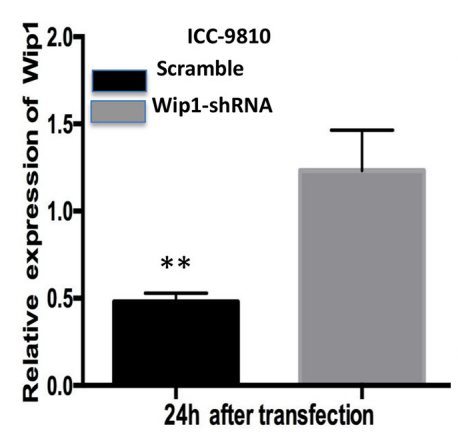

A

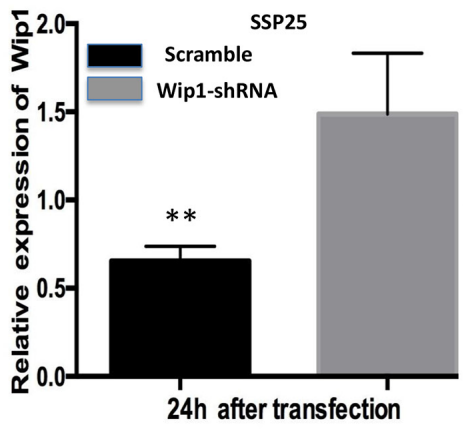

B

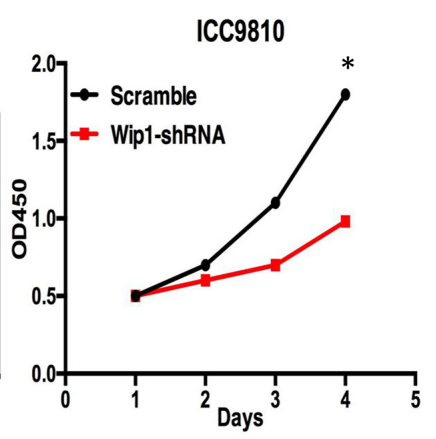

D
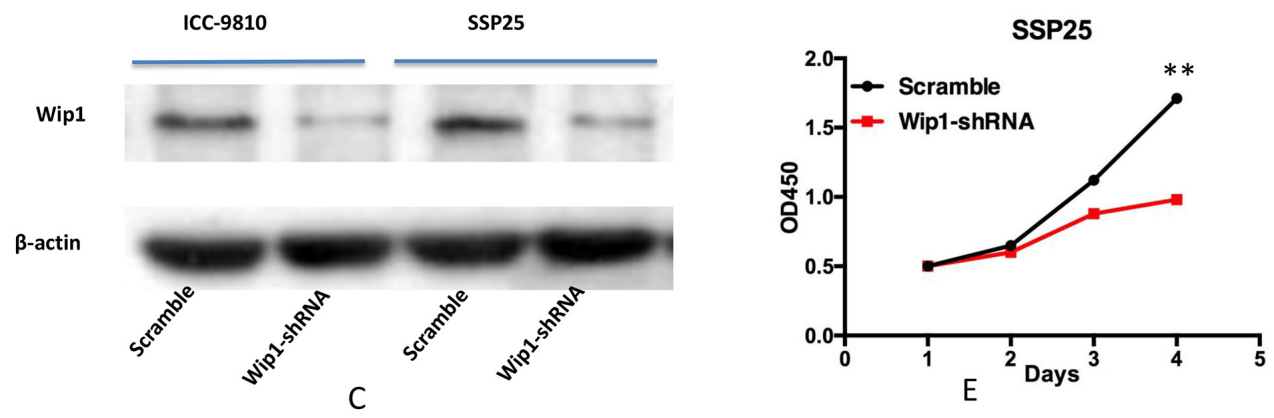

Figure 2: Transfection of Wip1-shRNA represses proliferation of ICC-9810 and SSP25 cells in vitro. Real time PCR analysis revealed that Wip1 mRNA in Wip1-shRNA ICC-9810 and SSP25 cells was significantly down- regulated (A,B) Similar results were obtained by Western blotting analysis (C) Down-regulation of Wip1 expression by Wip1-shRNA significantly inhibited the proliferation of ICC-9810 and SSP25 cells cells $(\mathbf{D}, \mathbf{E}) * \mathrm{P}<0.05, * * \mathrm{P}<0.001$.

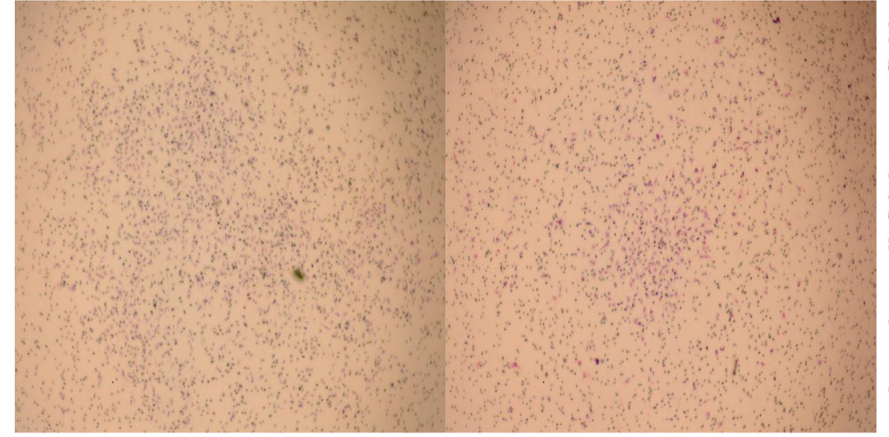

A

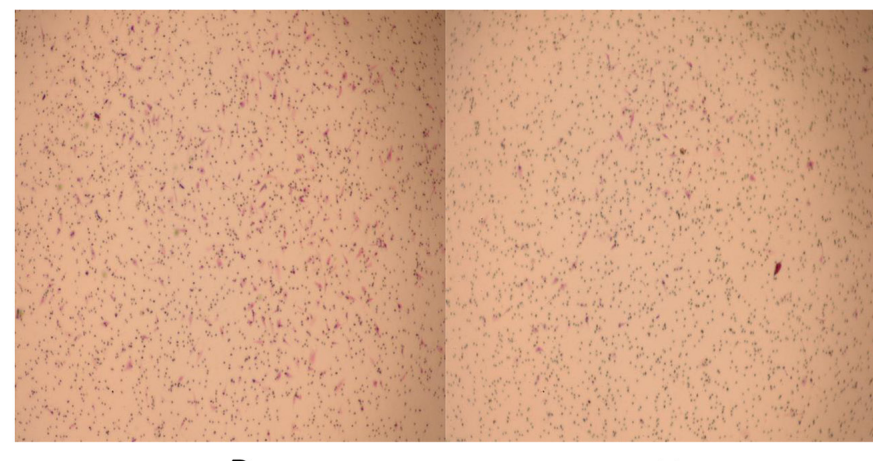

D

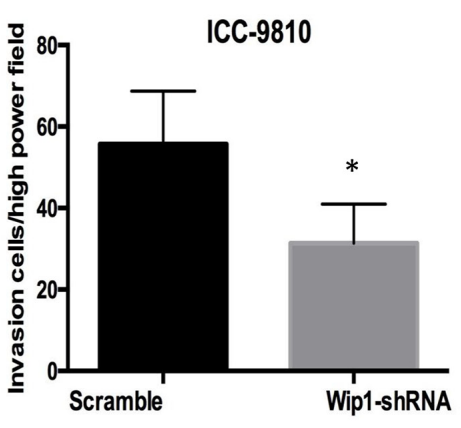

C

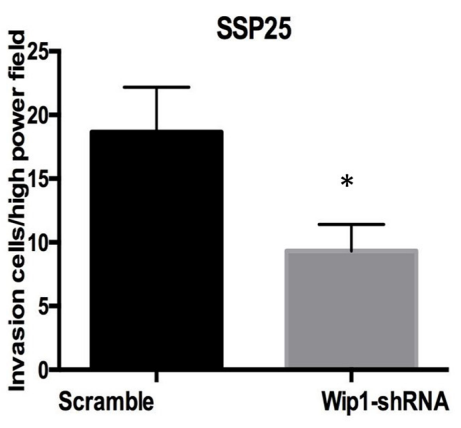

$\mathbf{F}$

Figure 3: Wip1 knockdown inhibited the invasive ability of ICC cells in vitro. Representative images of the invaded ICC-9810 and SSP25 cells in Matrigel invasion assays were taken at $\times 200$ magnification (A,B,D,E) Numbers of the invaded ICC-9810 and SSP25 cells per microscopic field $(\mathbf{C}, \mathbf{F}){ }^{*} \mathrm{p}<0.05$. 


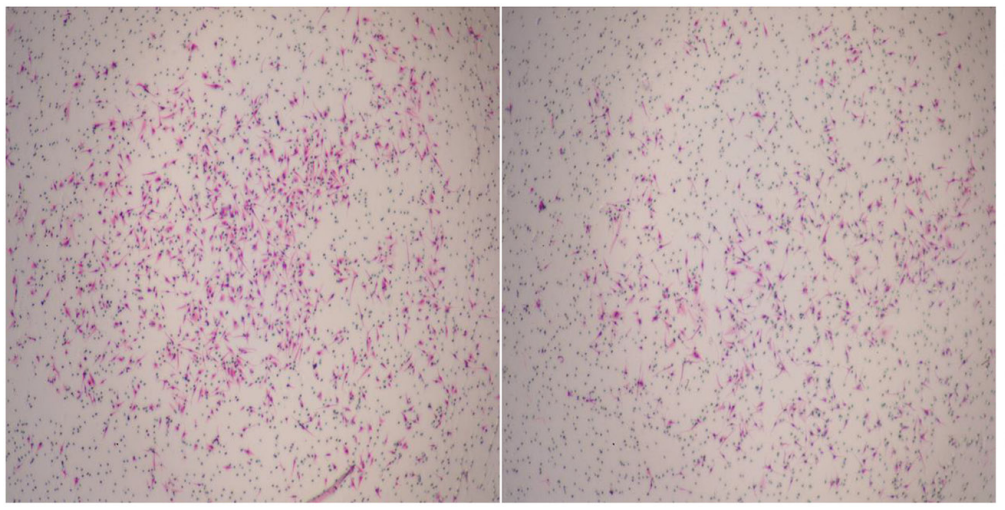

A

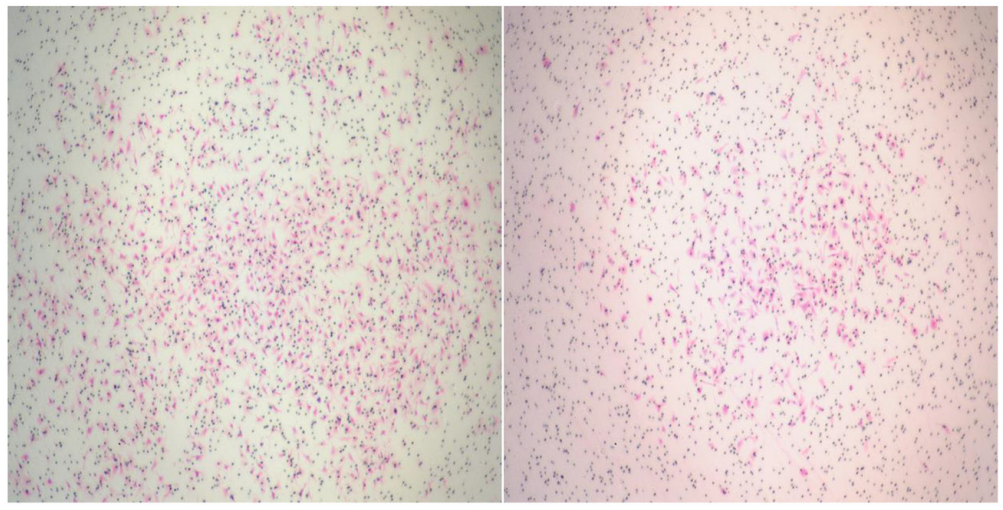

D

E

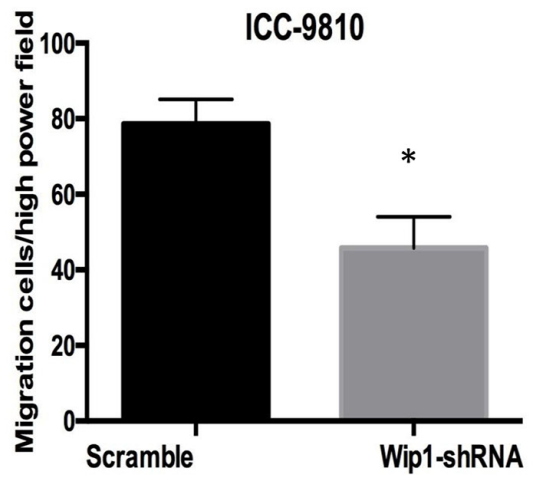

C

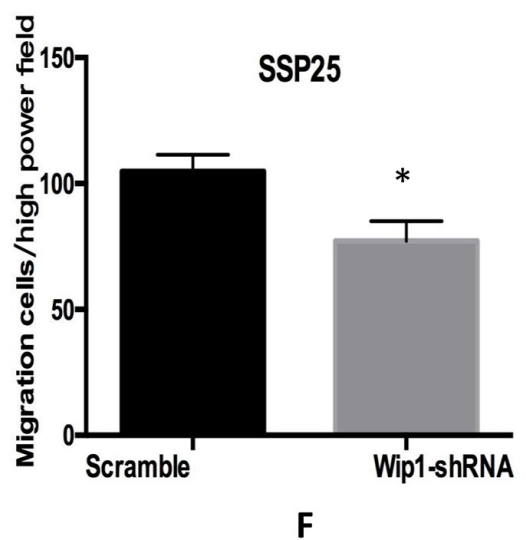

ICC-9810

G Scramble

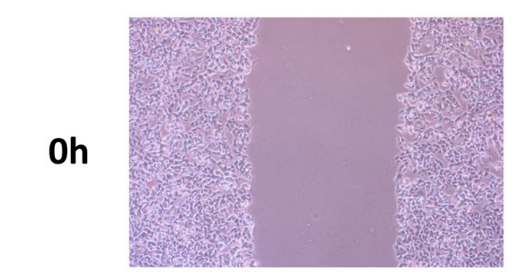

$24 h$
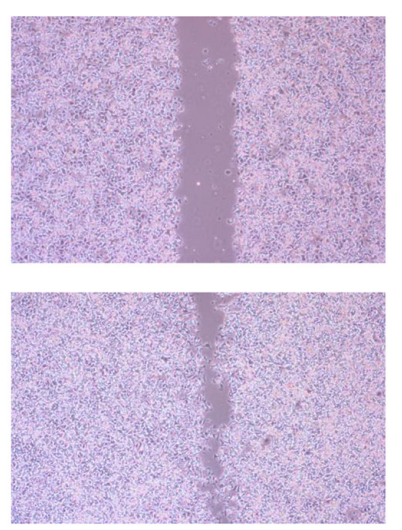

Wip1-shRNA
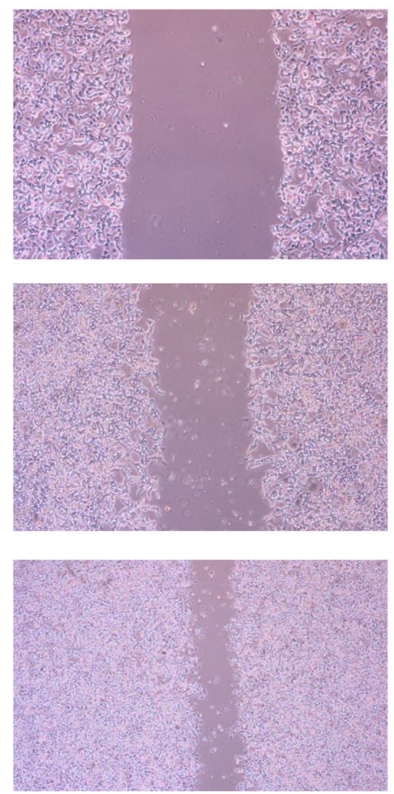

H

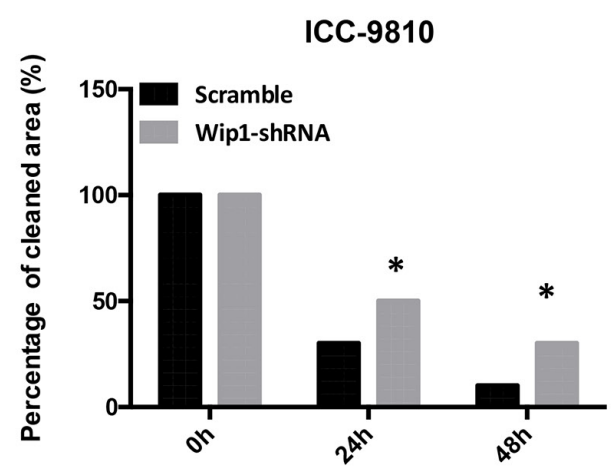

Figure 4: Wip1 knockdown inhibited the migration ability of ICC cells in vitro. Representative images of the migrate ICC9810 and SSP25 cells in Matrigel assays were taken at $\times 200$ magnification (A,B,D,E) Numbers of the invaded ICC-9810 and SSP25 cells per microscopic field (C,F). In a wound healing assay, ICC-9810 and SSP25 cells in the Wip1-shRNA group exhibited decreased migration ability compared with control group (G) Cells were monitored every $24 \mathrm{~h}$ for 2 days to evaluate the rate of migration into the scratched area $\mathbf{( H )} .{ }^{*} \mathrm{P}<0.05$. 
In this study, we indicated that the Wip1 expression in ICC was significantly associated with lymph metastasis and nerve invasion $(\mathrm{p}<0.001, \mathrm{p}=0.035$ respectively). Moreover, our data show that the wip1 was significantly correlated with P53 ( $p=0.014)$, CA-199 $(p=0.015)$ and MMP-2 $(p=0.008)$ expression. A body of evidence indicated that Wip1 was a P53-regulated oncogene, which inactivated downstream proteins including P38, P53, ATM, Chk2 and turn back the tumor cells to a homeostasis state when induced by environment stresses $[11,24,32]$. Here, we have indicated depletion of Wip1 show impaired proliferation and migration capacity in ICC cells. What's more, implantation of Wip1-shRNA ICC cell into mice inhibited tumorigenesis. This suggests down-expression of Wip1 inhibits ICC migration and invasion.

We next study the mechanism of wip1 in the oncogenesis and metastasis of ICC. In the present study, up-regulations of MMP-2 and CA199 are the markers for increased proliferation of cancer cells. Further results showed that Wip1 knock-down by Wip1-shRNA dramatically inhibited the invasion and migration of ICC9810 and SSP25 cells and decreased MMP-2 expression. MMP-2, as a key protein in the ECM and basement membrane, that can promote carcinoma cell invasion and metastasis [36, 37].

A body of evidence indicated that lymph node metastasis was one of the strongest prognostic factors associated with survival in ICC patients [38-40]. Most studies reported that lymph node metastasis has a powerful negative effect on survival in these patients [3, 38]. In this study, Wip1 expression levels were dramatic associated with increased lymph node metastasis. These data show that Wip1 promoted lymphatic metastasis in ICC patients. Furthermore, We demonstrated that Wip1shRNA significantly inhibited MMP-2 expression in ICC cells, which was in collaborate with a previous report that knock-down the expression Wip1 can inhibit migration and invasion target VEGF-C and MMP-9 pathway in salivary adenoid cystic carcinoma [41].
A

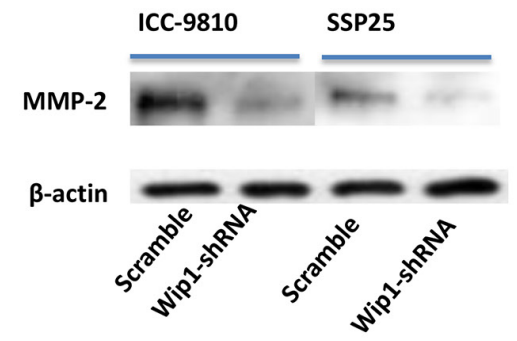

C

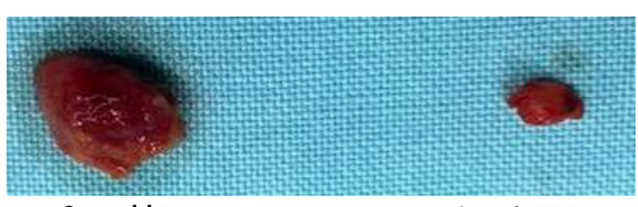

Scramble

Wip1-shRNA

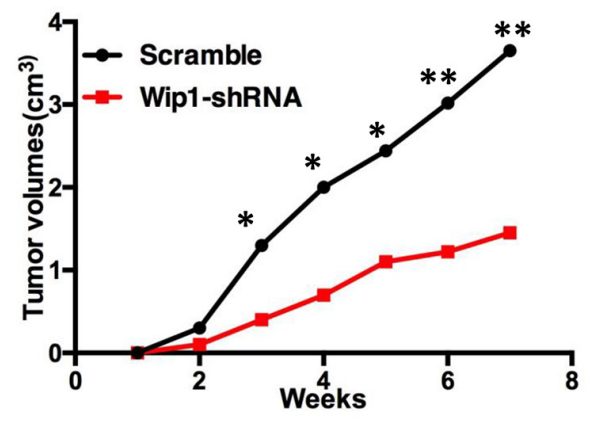

B

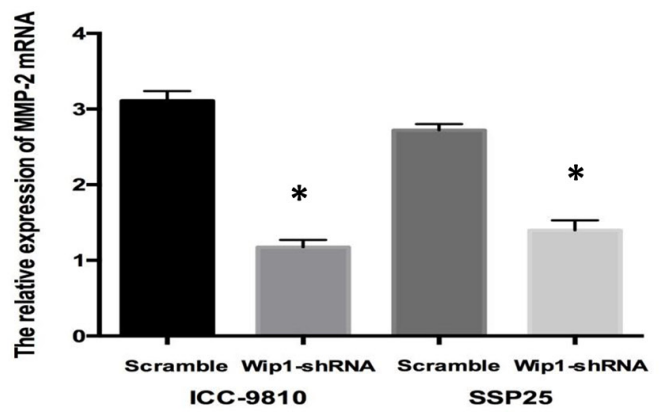

D

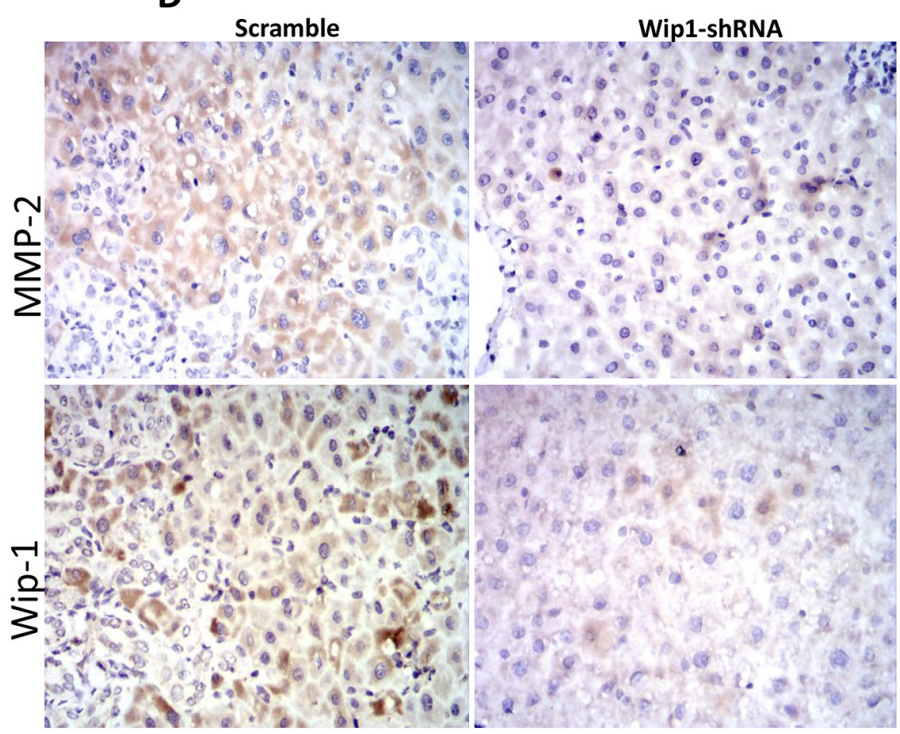

Figure 5: Transfection of Wip1-shRNA impaired ICC-9810 and SSP25 cell tumor formation through MMP-2 in vivo. Western blot/PCR revealed that shRNA-Wip1 remarkably decreased the levels of MMp-2 (A,B) Following down- regulation of Wip1 expression, ICC-9810 and SSP25 cells exhibited significantly diminished in vivo tumor formation ability compared with control cells (C, upper). Tumor size was measured every week. There was a significant reduction in relative tumor volume from shRNA-Wip1-treated animals when compared with untreated controls (C, down). The expression of Wip1/MMP-2 was positively correlated with subcutaneous tumor volume (D). ${ }^{*} \mathrm{P}<0.05$. 
At the histological level, ICC is characterized by an abundant stroma; i.e. the tumor microenvironment that notably includes components of the ECM, stromal cells and soluble factors [42]. On the other hand, MMPs (Matrix metalloproteinases) have an crucial effect in tumor cell invasion and metastasis by degrading ECM proteins [43]. MMP-2 is a secreted protein implicated in the destruction of broad range of ECM substrates in various cancers [44]. In this study, Wip1 knockdown inhibited ICC cell motility and invasion, and decreased the expression of EMT markers MMP-2. The regulation of MMP-2 expression is via various transcription factors such as nuclear factor $\kappa \mathrm{B}$ $(\mathrm{NF \kappa} \mathrm{B})$, mitogen-activated protein kinases (MAPKs), and phosphoinositide-3 kinase/protein kinase B (PI3K/AKT) pathways $[44,45]$. Based on above data, we suggest that the high level of Wip1 may induce ICC cells invasion and metastasis by up-regulating the MMP-2 expression.

In conclusion, our study demonstrate that wip1 expression is a crucial regulator in the progression of human ICC; further investigations show Wip1 exerts its pro-invasion function at least in part through the MMP-2 signaling pathway, suggesting that Wip1 may be a potential target for ICC therapy.

\section{MATERIALS AND METHODS}

\section{Patients and tissue source}

Sixty primary ICC and distant normal tissue samples were obtained from ICC patients that underwent radical surgical resection between June 2014 and July 2016 at The Department of Hepatobiliary Surgery, Hunan Provincial People's Hospital/The First Affiliated Hospital of Hunan Normal University. None of the patients received any preoperative chemo- and radiotherapy, or other medical interventions. The clinicopathological characteristics of the patients were retrieved from the medical records and are summarized in Table 1. The fresh specimens of tumor tissue or adjacent normal epithelium $1 \mathrm{~cm}$ apart from the tumor edge were immediately taken after the surgery, which was fixed in 4\% paraformaldehyde solution, and then embedded in paraffin for immunohistochemistry. This study was reviewed and approved by the Ethics Committee of The Hunan Normal University (NO:566789), and an informed consent form was signed by each patient before surgery. All methods were carried out in accordance with relevant guidelines and regulations of The Hunan Normal University (Two edition 2013).

\section{Evaluation of immunohistochemical staining}

The immunohistochemical staining of Wip1 on ICC tissue was evaluated in accordance with our previous studies [14, 19]. Briefly, all tissue sections were reviewed under a light microscopy and scored for at least five fields at a $\times 400$ magnification independently by two pathologists who were unaware of any clinical or outcome data.
The scoring system was as follows: the percentage of positively staining cells was graded as - (no staining, Wip1-negative), $+(>0$ and $\leq 25 \%$ of cells positive, weak Wip1-positive), $++(>25$ and $\leq 75 \%$ of cells positive, moderate Wip1-positive), and $+++(>75 \%$ of cells positive, strong Wip1-positive).

\section{Reagents and antibodies}

DMEM, lipofectamine 2000, trypsin, trizol reagent, penicillin/streptomycin and fetal bovine serum (FBS) were from Invitrogen. The rabbit polyclonal anti-Wip1 and rabbit polyclonal anti-MMP-2 (Cell Signaling Technology, Beverly, MA) was used at the dilution of $1: 400$, while $\beta$-actin (Santa Cruz Biotechnology, Santa Cruz, CA) was used as a loading control. In accordance with Wip1 gene sequence in the NCBI database and siRNA design principles, the Wip1specific shRNAs was designed and synthesized by Shanghai ShengGong Co., Ltd., DNA oligonucleotides used to generate shRNAs against the open reading frame of mRNA were 5'-CCCTTCTCGTGTTTGCTTAAA-3' (for Wip1) to silence the expression of Wip1. In addition, a negative shRNA control that shared no homology to siRNAWip1 genome sequence was designed and synthesized by Shanghai ShengGong Co. Ltd.

\section{Cell lines and culture}

ICC-9810 and SSP25 were purchased from the Type Culture Collection of the Chinese Academy of Sciences (Shanghai, China); BEC (humanbiliary epithelial cell) were preserved in our laboratory. Cells were grown in DMEM supplemented with $10 \% \mathrm{FBS}$ and penicillin or rstreptomycin $(100 \mathrm{U} / \mathrm{mL} / 50 \mathrm{mg} / \mathrm{mL})$ at $5 \% \mathrm{CO} 2$ and $37^{\circ} \mathrm{C}$.

\section{Cell proliferation, invasion, migration, western blot and quantitative real-time PCR assays}

Cell proliferation, invasion, migration assay were carried out as our previously described [14]. Total protein was extracted using RIPA buffer and protein expression was analyzed by western blot as our described study [14]. Total RNA was extracted and purified from cell lines according to the manufacturer's instructions and our previous report [14]. $\beta$-actin served as an endogenous control. The sequences of gene specific primers for Wip1 (forward, 5'- GAAGGATGACTTTGTCAG -3'; reverse, 5' - CCCAGACTTGTTCATTAC-3') and $\beta$-actin (forward, 5' - CATCCTGCGTCTGGACCTGG -3'; reverse, 5'TAATGTCACGCACGATTTCC -3') were designed using NCBI Primer-BLAST.

\section{Wound healing assay}

Wound healing assay was performed to evaluate the cell migratory capacity. In brief, ICC-9810/SSP25 cells were cultured to full confluence. Wounds of approximately 
$1 \mathrm{~mm}$ width were created with a plastic scriber, and cells were washed. After cultured for 24/48 hours, cells were fixed and observed under a microscope.

\section{Xenografts in nude mice}

All animal experiments described in this study was performed in accordance with protocols approved by the Institutional Animal Care and Use Committee at Hunan Normal University. Briery, $5 \times 10^{6}$ shRNA-Wip1 ICC cells and control cells were suspended in $100 \mu \mathrm{PBS}$ and were injected subcutaneously into six female nude mice (Balb/c nu/nu) (3-4 weeks old), respectively. Tumor volumes were monitored every 7 days by measuring the length and width with a caliper and using the formula (width 2 ) $\times$ length $/ 2$. Mice were sacrificed 7 weeks after injection, and the tumors were isolated and measured.

\section{Statistical analysis}

Statistical analyses were performed using GraphPad Prism6 software (Graphpad Software, Inc., La Jolla, CA, USA). Values were expressed as mean \pm SD using the Student's t-test. The correlation analysis was examined using spearman rank correlation test. Data are presented as the means \pm SD from three independent experiments. The $p<0.05$ was considered statistically significant.

\section{Author contributions}

BJ are fully responsible for the study designing, experiment adjustment, drafting and finalizing the manuscript. SLL, ZCX, WC and ZKL performed most of the experiments involved. BZ, HL, ZLH, PL carried out transfection assays and some protein measurement by Western blot and statistical analysis. WC, CP, YGW conducted the densitometry, statistical analysis and participated in coordination manuscript. SLL, SLX, SQS, SLX and BJ coordinated and provided important suggestions including some reagents, critical read the manuscript. All authors read and approved the final manuscript.

\section{ACKNOWLEDGMENTS}

This work was supported by the Research Foundation of Education Bureau of Hunan Province, China (Grant No. 15A114) and supported by Hunan Science and Technology Plan Project (Grant No. 2015SK2050) and supported by the Foundation of the National Nature Science Foundation of China (Grant No.81372157).

\section{CONFLICTS OF INTEREST}

The authors declare that they have no financial or commercial conflicts of interest.

\section{REFERENCES}

1. Shaib YH, Davila JA, McGlynn K, El-Serag HB. Rising incidence of intrahepatic cholangiocarcinoma in the United States: a true increase? J Hepatol. 2004; 40: 472-477.

2. Wang Y, Li J, Xia Y, Gong R, Wang K, Yan Z, Wan X, Liu G, Wu D, Shi L, Lau W, Wu M, Shen F. Prognostic nomogram for intrahepatic cholangiocarcinoma after partial hepatectomy. J Clin Oncol. 2013; 31: 1188-1195.

3. Doussot A, Lim C, Gómez Gavara C, Fuks D, Farges O, Regimbeau JM, Azoulay D, AFC-IHCC Study Group. Multicentre study of the impact of morbidity on longterm survival following hepatectomy for intrahepatic cholangiocarcinoma. Br J Surg. 2016; 103: 1887-1894.

4. Ghiassi-Nejad Z, Moshier E, Schwartz M, Buckstein M. Definitive chemoradiation therapy in the treatment of unresectable intrahepatic cholangiocarcinoma: a national cancer data base study. Int J Radiat Oncol Biol Phys. 2016; 96: E211-E212.

5. Sapisochin G, Facciuto M, Rubbia-Brandt L, Marti J, Mehta N, Yao FY, Vibert E, Cherqui D, Grant DR, Hernandez-Alejandro R, Dale CH, Cucchetti A, Pinna A, et al. Liver transplantation for "very early" intrahepatic cholangiocarcinoma: International retrospective study supporting a prospective assessment. Hepatology. 2016; 64: $1178-1188$.

6. Xiao H, Tong R, Yang B, Lv Z, Du C, Peng C, Ding C, Cheng S, Zhou L, Xie H, Wu J, Zheng S. TAZ regulates cell proliferation and sensitivity to vitamin D3 in intrahepatic cholangiocarcinoma. Cancer Lett. 2016; 381: 370-379.

7. Brazina J, Svadlenka J, Macurek L, Andera L, Hodny Z, Bartek J, Hanzlikova H. DNA damage-induced regulatory interplay between DAXX, p53, ATM kinase and Wip1 phosphatase. Cell Cycle. 2015; 14: 375-387.

8. Chong KH, Samarasinghe S, Kulasiri D. Mathematical modelling of p53 basal dynamics and DNA damage response. Math Biosci. 2015; 259: 27-42.

9. Buss MC, Remke M, Lee J, Gandhi K, Schniederjan MJ, Kool M, Northcott PA, Pfister SM, Taylor MD, Castellino $\mathrm{RC}$. The WIP1 oncogene promotes progression and invasion of aggressive medulloblastoma variants. Oncogene. 2015; 34: 1126-1140.

10. Cao R, Zhang J, Zhang M, Chen X. PPM1D regulates p21 expression via dephoshporylation at serine 123. Cell Cycle. 2015; 14: 641-647.

11. Goloudina AR, Kochetkova EY, Pospelova TV, Demidov ON. Wip1 phosphatase: between p53 and MAPK kinases pathways. Oncotarget. 2016; 7: 31563-31571. doi: 10.18632/ oncotarget.7325.

12. Chen Z, Yi W, Morita Y, Wang H, Cong Y, Liu JP, Xiao Z, Rudolph KL, Cheng T, Ju Z. Wip1 deficiency impairs haematopoietic stem cell function via $\mathrm{p} 53$ and mTORC1 pathways. Nat Commun. 2015; 6: 6808. 
13. Gilmartin AG, Faitg TH, Richter M, Groy A, Seefeld MA, Darcy MG, Peng X, Federowicz K, Yang J, Zhang SY, Minthorn E, Jaworski JP, Schaber M, et al. Allosteric Wip1 phosphatase inhibition through flap-subdomain interaction. Nat Chem Biol. 2014; 10: 181-187.

14. Liu S, Qi L, Han W, Wan X, Jiang S, Li Y, Xie Y, Liu L, Zeng F, Liu Z, Zu X. Overexpression of wipl is associated with biologic behavior in human clear cell renal cell carcinoma. PLoS One. 2014; 9: e110218.

15. Emelyanov A, Bulavin DV. Wip1 phosphatase in breast cancer. Oncogene. 2015; 34: 4429-4438.

16. Fu Z, Sun G, Gu T. Proto-oncogene Wip1, a member of a new family of proliferative genes in NSCLC and its clinical significance. Tumour Biol. 2014; 35: 2975-2981.

17. Yin S, Wang P, Yang L, Liu Y, Wang Y, Liu M, Qi Z, Meng J, Shi TY, Yang G, Zang R. Wip1 suppresses ovarian cancer metastasis through the ATM/AKT/Snail mediated signaling. Oncotarget. 2016; 7: 29359-29370. doi: 10.18632/ oncotarget.8833.

18. Richter M, Dayaram T, Gilmartin AG, Ganji G, Pemmasani SK, Van Der Key H, Shohet JM, Donehower LA, Kumar R. WIP1 phosphatase as a potential therapeutic target in neuroblastoma. PLoS One. 2015; 10: e0115635.

19. Liu S, Qi L, Yu Q, Song Y, Han W, Zu X, Jiang S, Yuan J, Zeng F, Xie Y. Survivin and HLA-I expression predicts survival of patients with clear cell renal cell carcinoma. Tumour Biol. 2014; 35: 8281-8288.

20. Sun B, Rong R, Jiang H, Zhang H, Wang Y, Bai X, Zhang M, Ma J, Xia S, Shu W, Zhang L, Leng J. Prostaglandin E2 receptor EP1 phosphorylate CREB and mediates MMP2 expression in human cholangiocarcinoma cells. Mol Cell Biochem. 2013; 378: 195-203.

21. Wang Q, Tang H, Yin S, Dong C. Downregulation of microRNA-138 enhances the proliferation, migration and invasion of cholangiocarcinoma cells through the upregulation of RhoC/p-ERK/MMP-2/MMP-9. Oncol Rep. 2013; 29: 2046-2052.

22. Fiscella M, Zhang H, Fan S, Sakaguchi K, Shen S, Mercer WE, Vande Woude GF, O'Connor PM, Appella E. Wip1, a novel human protein phosphatase that is induced in response to ionizing radiation in a p53-dependent manner. Proc Natl Acad Sci U S A. 1997; 94: 6048-6053.

23. Lin J, Zhang Q, Lu Y, Xue W, Xu Y, Zhu Y, Hu X. Downregulation of HIPK2 increases resistance of bladder cancer cell to cisplatin by regulating Wip1. PLoS One. 2014; 9: e98418.

24. Elias J, Dimitrio L, Clairambault J, Natalini R. The dynamics of p53 in single cells: physiologically based ODE and reaction-diffusion PDE models. Phys Biol. 2014; 11: 045001.

25. Pechackova S, Burdova K, Benada J, Kleiblova P, Jenikova G, Macurek L. Inhibition of WIP1 phosphatase sensitizes breast cancer cells to genotoxic stress and to MDM2 antagonist nutlin-3. Oncotarget. 2016; 7: 14458-14475. doi: 10.18632/oncotarget.7363.

26. Liu B, Yan S, Jia Y, Ma J, Wu S, Xu Y, Shang M, Mao A. TLR2 promotes human intrahepatic cholangiocarcinoma cell migration and invasion by modulating NF-kappaB pathway-mediated inflammatory responses. FEBS J. 2016; 283: 3839-3850.

27. Jackson MW, Amini A, Jones BL, Rusthoven CG, Schefter TE, Goodman KA. Treatment selection and survival outcomes with and without radiation for unresectable, localized intrahepatic cholangiocarcinoma. Cancer J. 2016; 22: 237-242.

28. Ma KW, Cheung TT, She WH, Chok KS, Chan AC, Ng IO, Chan SC, Lo CM. The effect of wide resection margin in patients with intrahepatic cholangiocarcinoma: a singlecenter experience. Medicine (Baltimore). 2016; 95: e4133.

29. Miyata A, Sakamoto Y, Yamamoto S, Akamatsu N, Arita J, Kaneko J, Hasegawa K, Kokudo N. Aggressive hemihepatectomy combined with resection and reconstruction of middle hepatic vein for intrahepatic cholangiocarcinoma. Ann Surg Oncol. 2016; 23: 494-500.

30. Yamashita S, Koay EJ, Passot G, Shroff R, Raghav KP, Conrad C, Chun YS, Aloia TA, Tao R, Kaseb A, Javle $\mathrm{M}$, Crane $\mathrm{CH}$, Vauthey JN. Local therapy reduces the risk of liver failure and improves survival in patients with intrahepatic cholangiocarcinoma: a comprehensive analysis of 362 consecutive patients. Cancer. 2016; 123 : 1354-1362.

31. Yang F, Yin Y, Wang F, Wang Y, Zhang L, Tang Y, Sun S. miR-17-5p Promotes migration of human hepatocellular carcinoma cells through the p38 mitogen-activated protein kinase-heat shock protein 27 pathway. Hepatology. 2010; 51: 1614-1623.

32. Zhang L, Liu L, He Z, Li G, Liu J, Song Z, Jin H, Rudolph KL, Yang H, Mao Y, Zhang L, Zhang H, Xiao Z, Ju Z. Inhibition of wild-type $\mathrm{p} 53$-induced phosphatase 1 promotes liver regeneration in mice by direct activation of mammalian target of rapamycin. Hepatology. 2015; 61: 2030-2041.

33. Li GB, Zhang XL, Yuan L, Jiao QQ, Liu DJ, Liu J. Protein phosphatase magnesium-dependent 1delta (PPM1D) mRNA expression is a prognosis marker for hepatocellular carcinoma. PLoS One. 2013; 8: e60775.

34. Xu Z, Cao C, Xia H, Shi S, Hong L, Wei X, Gu D, Bian J, Liu Z, Huang W, Zhang Y, He S, Lee NP, Chen J. Protein phosphatase magnesium-dependent 1delta is a novel tumor marker and target in hepatocellular carcinoma. Front Med. 2016; 10: 52-60.

35. Nannenga B, Lu X, Dumble M, Van Maanen M, Nguyen TA, Sutton R, Kumar TR, Donehower LA. Augmented cancer resistance and DNA damage response phenotypes in PPM1D null mice. Mol Carcinog. 2006; 45: 594-604.

36. Onodera M, Zen Y, Harada K, Sato Y, Ikeda H, Itatsu K, Sato H, Ohta T, Asaka M, Nakanuma Y. Fascin is involved in tumor necrosis factor-alpha-dependent production of 
MMP9 in cholangiocarcinoma. Lab Invest. 2009; 89: 1261-1274.

37. Shi RY, Yang XR, Shen QJ, Yang LX, Xu Y, Qiu SJ, Sun YF, Zhang X, Wang Z, Zhu K, Qin WX, Tang ZY, Fan J, Zhou J. High expression of Dickkopf-related protein 1 is related to lymphatic metastasis and indicates poor prognosis in intrahepatic cholangiocarcinoma patients after surgery. Cancer. 2013; 119: 993-1003.

38. Giuliante F, Ardito F, Guglielmi A, Aldrighetti L, Ferrero A, Calise F, Giulini SM, Jovine E, Breccia C, De Rose AM, Pinna AD, Nuzzo G. Association of lymph node status with survival in patients after liver resection for hilar cholangiocarcinoma in an Italian multicenter analysis. JAMA Surg. 151: 916-922.

39. Cuneo KC, Lawrence TS. Growing evidence supports the use of radiation therapy in unresectable intrahepatic cholangiocarcinoma. Cancer J. 2016; 22: 243-244.

40. Grassberger C, Wo JY, Hato T, Bortfeld T, Wolfgang JA, Zhu AX, Duda DG, Hong TI. Treatment-induced changes in circulating lymphocyte populations associate with survival of patients with hepatocellular carcinoma (HCC) and intrahepatic cholangiocarcinoma (ICC) treated with hypofractionated proton therapy (HPT). Int J Radiat Oncol Biol Phys. 2016; 96: S142.
41. Tang YL, Liu X, Gao SY, Feng H, Jiang YP, Wang SS, Yang J, Jiang J, Ma XR, Tang YJ, Chen Y, Liang XH. WIP1 stimulates migration and invasion of salivary adenoid cystic carcinoma by inducing MMP-9 and VEGF-C. Oncotarget. 2015; 6: 9031-9044. doi: 10.18632/oncotarget.3320.

42. Sirica AE, Dumur CI, Campbell DJ, Almenara JA, Ogunwobi OO, Dewitt JL. Intrahepatic cholangiocarcinoma progression: prognostic factors and basic mechanisms. Clin Gastroenterol Hepatol. 2009; 7: S68-78.

43. Rizvi S, Borad MJ, Patel T, Gores GJ. Cholangiocarcinoma: molecular pathways and therapeutic opportunities. Semin Liver Dis. 2014; 34: 456-464.

44. Rybarczyk P, Vanlaeys A, Brassart B, Dhennin-Duthille I, Chatelain D, Sevestre H, Ouadid-Ahidouch H, Gautier. The transient receptor potential melastatin 7 channel regulates pancreatic cancer cell invasion through the Hsp90alpha/ uPA/MMP2 pathway. Neoplasia. 19: 288-300.

45. Weng CJ, Chau CF, Hsieh YS, Yang SF, Yen GC. Lucidenic acid inhibits PMA-induced invasion of human hepatoma cells through inactivating MAPK/ERK signal transduction pathway and reducing binding activities of NF-kappaB and AP-1. Carcinogenesis. 2008; 29: 147-156. 